\title{
Conceptualizing a Model for Teacher Team Learning: The Promise of Integration of Diversity of Perspectives During Team Learning
}

\author{
Hyunjin Choi \\ Columbia University \\ Eleanor Drago-Severson \\ Columbia University \\ Victoria J. Marsick \\ Columbia University
}

\begin{abstract}
Many studies have emphasized that the integration of divergent perspectives is the central to teacher team learning, but it is difficult for teacher teams. This is because it is necessary to consider the multi-layers of team learning to foster the integration. However, existing research has focused only on a unidimensional aspect. Therefore, we conceptualize a comprehensive theoretical model for teacher team learning with focus on integration of perspective by incorporating multiple aspects, including (a) not only the cognitive dimension, but also the affective, relational and motivational dimensions and (b) not only a team level, but also a system (organizational) level.
\end{abstract}

Keywords: teacher teams, team learning model, team diversity integration, conceptual paper

\section{INTRODUCTION}

Teaming and building more effective ways to team are at the forefront of education today (DragoSeverson et al, 2018). Scholars and practitioners alike maintain that it is essential that principals and teacher leaders allocate and prioritize time for teachers to collaborate in teams (Hargreaves, 2019; Hargreaves \& O'Connor, 2018; Johnston et al., 2007; Troen \& Boles, 2012). In fact, in today's world, teachers engage in various configurations of teams and teaming, including "team teaching, pairing veteran and new teachers, forming school leadership teams, examining student work and/or teacher practice, or working collaboratively on reform or improvement issues" (Drago-Severson, 2009, p.72). And historically and presently, the existing research has highlighted that team learning plays a crucial role in helping teachers to engage in effective teams and teaming (Bouwmans et al, 2017; Decuyper et al, 2010; Runhaar et al, 2014; Vangrieken et al, 2016). This has become even more important today with teams and teaming being online due to a triple pandemic (Bouffard, 2020). Regardless of difference in terminology and foci, team learning here commonly refers to a process and/or outcome of developing shared understanding around team issues, tasks, and problems and/or team capacity to work together (Knapp, 2010; Lieberman \& Miller, 2011; Ohlssol, 2013; Vangrieken et al, 2016; Zimmermann et al, 2019). 
Importantly, many studies emphasize that integration of divergent and different perspectives is the central part of team learning (Edmondson \& Harvey, 2018; Shippers et al, 2017; Watkins \& Marsick, 2010). This is because the diversity of perspectives within a team enables members to (a) engage in various perspectives and gain access to a quality of cognitive resources, (b) support each other better, and (c) increase creativity, problem-solving, and decision-making capacity (van Knippenberg \& Mell, 2016; Widmann \& Mulder, 2018; Watkins \& Marsick, 2010; Zimmerman et al., 2019). For instance, Zimmerman and colleagues (2019) assert that team integration of divergent perspectives improves teacher teams' capacity to address educational challenges that they face today since many of the educational challengessuch as "preparing students for jobs that have yet to be defined or reimagining education in a highly technological society" (p.112) - emerge from nonlinear causal relationships, in which myriad causal relations are intertwined with rich complexity. In order to address these complicated challenges, incorporating multiple voices coming from diverse backgrounds is more helpful in comparison to considering a sole voice embedded in a few as multiple perspectives enable team members to create richer responses to the perplexities by looking at multi-dimensions of their challenges (Garmston \& Wellman, 2016; Page, 2018; Zimmerman et al, 2019).

Yet, regardless of its importance, it is not easy for teacher teams to integrate divergent perspectives in the middle of team learning (Achinstein, 2002; Drago-Severson et al, 2018). In other words, many studies have revealed that different perspectives coming from various kinds of diversity (e.g., demographic backgrounds, task-relevant backgrounds, developmental stages, and contexts) can hinder the team's integrative process by (a) engaging members in team dilemmas, (b) creating affective conflicts, (c) hindering members' motivation to learn from different perspectives, and (d) decreasing interactions and communication with different members (Drach-Zahavy \& Somech, 2001; Drago-Severson et al, 2018; Lortie, 2002; Pieterse et al., 2011). For instance, many teacher teams' experience of team dilemma hinders members' ability to learn from each other and develop shared understanding during their teaming due to difference of individual members' internal meaning making system that influences how, for example, individual team members will make sense of their experiences on a team, including how they will experience conflict as well as what their preoccupying concern will be as they engage in the practice of teaming (Drago-Severson et al, 2018). Additionally, many teacher teams often fail to create shared understandings of innovative teaching methods and strategies because of emotional conflicts coming from school tenure heterogeneity (Drach-Zahavy \& Somech, 2001; Weiss et al, 1992). Teacher teams sometimes divide members into sub-groups aligned with their school tenure, and this increases emotional conflicts among members (Drach-Zahavy \& Somech, 2001; Weiss et al, 1992). Furthermore, teachers who have their own individual contexts to teach (e.g., a class) can be less motivated to work with other teachers and learn from different perspectives by assuming that the different ideas and perspectives offered by outsiders (e.g., teachers who teach different classes or students) who do not know much about all of the unique and complicated contextual factors is not applicable to their contexts (Eisner, 1998; Hur, 2008; Lee et al, 2012; Lortie, 2002). Sometimes, teacher team members even fail to engage in team processes to integrate their team diversity by reducing interactions and connections with the different members who are assigned as outgroups (Pieterse et al, 2011; van Knippenberg \& Mell, 2016). Teacher team members can view team diversity as "a potential source of us vs them distinction" (Pieterse et al, 2011, p. 154) and categorize different others as outgroups based on well-developed stereotypes that the members hold as well as demographic background (Pieterse et al, 2011; van Knippenberg \& Mell, 2016).

Here, the challenges that teacher teams often face while integrating divergent perspectives are connected to multi-dimensions of team learning, including (a) the constructive-developmental aspect to address team dilemma coming from developmental diversity, (b) the affective aspect to alleviate affective conflicts coming from team tenure diversity, (c) the motivational aspect to deal with a decrease in motivation to learn from different perspective, and (b) the interactive and relational aspect to resolve a decrease in interaction and communication to work with different members. And, this implies that it is necessary to consider multi-layers of teacher team learning to foster integration of divergent perspectives during teacher team learning. Indeed, many theories and studies in various other areas suggest that considering multilayers of team learning can give us in-depth insight to understand integration of different 
perspectives during team learning (Alderfer, 2011; Edmondson \& Harvey, 2018; Fleming, 2014; Kasl \& Yorks, 2012; Wells, 1995). For instance, in the area of adult learning focusing on higher education and business sectors, Kasl and Yorks (2012) argue that as opposed to pragmatism that has been the dominant paradigm and focuses on cognitive (mental), rational, and linguistic aspects of learning, the construct of presentational knowing in phenomenology - which emphasizes the affective, intuitive, and extralinguistic dimension of learning - can help us to alleviate the paradox of diversity of learners. Additionally, Fleming (2014) argues the idea of recognition, which highlights the relational aspect of learning, can soften "high rationality of the critiqued version of transformative learning" (p. 21), whereby people challenge each other's ideas, perceptions, and perspectives. Furthermore, in the area of socio-psychology, Alderfer (2011) and Wells (1995) claim that individuals in groups serve as representatives of divergent identity or organizational groups, meaning that interpersonal conflicts among group members may function as representatives of conflicts or relationship between upper-level groups that each group member comes from (Alderfer, 2011; Wells, 1995). Hence, in order to resolve conflicts coming from differences in groups, it is important to take a systemic approach that incorporates various levels, not only intrapersonal, interpersonal, and group level, but also intergroup and inter-organizational levels (Alderfer, 2011; Wells, 1995).

Nonetheless, most studies on teacher teams and team learning focus on unidimensional team learning. This includes studies that merely highlight (a) a cognitive level of learning (e.g., Ohlsson, 2013), (b) team learning at a team level (e.g., Voogt et al, 2011), or (c) experiential learning that are limited to problemsolving and/or reflection (e.g., Gregory, 2010). By employing these frameworks that each highlight a single dimension of team learning, it is difficult to understand and inform the practice of integration of divergent perspectives in teacher team learning, where multiple layers are intertwined with rich complexity.

Therefore, in this paper, our purpose is to build a more comprehensive model for teacher team learning-where integration of divergent and different perspectives is central-by considering the complexity of teacher team learning. In order to achieve this ambitious goal, in the first section, we discuss major tenants from theories and research in the fields of adult learning, socio-psychology, social cognition, social culture, and sociolinguistics that emphasize some of the multi-dimensional aspects of team learning, while examining how these principles can inform the practice of teacher team learning. The multilayers of team learning here entail (a) not only a cognitive aspect, but also motivational, affective, or interactive and relational aspects of team learning, (b) not only a team level but also an organizational level that teams are embedded in, and (c) not only experiential learning, but also other types of learning, including transformative or self-directed learning. More specifically, we employ Dechant \& Marsick's (1993) empirical model of team learning as a central focus to illuminate multi-layers of teacher team learning. This is because this model presents comprehensive aspects of team learning, including (a) both learning process and outcome, (b) various types of learning, such as empirical learning (adding to existing ways of thinking or constructing new ways of thinking) and transformative learning (transforming existing ways of thinking), and (c) both a micro-level of learning (team learning processes) and a systemic-level that influences the process (team and organizational conditions) (Dechant \& Marsick, 1993; Kasl et al, 1997). In addition to Dechant \& Marsick's (1993) empirical model, we also explore other theories and researchwhich reveal crucial aspects of teacher team learning that the empirical model does not cover, including affective, motivational, and interactive and relational aspect of team learning. Next, in the second section, we synthesize multi-dimensions of teacher team learning (discussed in the first section) into a coherent theoretical framework for teacher team learning with a focus on integration of divergent and different perspectives.

When exploring the existing literature to build the conceptual framework for teacher team learning, we selected and explored most common or well-regarded theories and research through "snowball sampling" (Neumerski, 2013, p.316). In the conceptual paper that investigated "what scholars know and do not know about instructional leadership" (p.310) in order to offer implications for future research, Neumerski (2013) employed snowball sampling to seek related literature for the study and described it as a process where one searches to find additional related resources by carefully following an author's personal knowledge, his/her colleagues' suggestion, or citations of the published and presented theories and research that had been previously reviewed by him/her. We used Neumerski's (2013) description of "snowball sampling" (p. 316). 
In other words, in this paper, we included and examined books, articles, dissertations, and presentations, which were located in (a) selections of readings in course syllabi of scholars who are leaders in the field of adult learning and teach at the research university the first author attends, (b) selections of research in metaanalysis research on teacher collaboration (e.g., Vangrieken et al, 2015), and (c) citations and references in the studies that we had previously reviewed. Moreover, we also included literature by entering the following keywords with no data restrictions into academic search engines (e.g., Google Scholar, Web of Science, ERIC, ProQuest) (Opengart, 2005): teacher team learning, teacher team, team learning, group learning, and collective learning. Here, although team learning is a subset of group learning and collective learning (Garavan \& McCarthy, 2008; Watkins \& Marsick, 2010; Knapp, 2010), in this research, we also explored theories, studies, and ideas of group learning and collective learning but only if they were associated with team learning.

\section{MULTI-LAYERS OF TEACHER TEAM LEARNING}

The primary purpose of this research was to develop a conceptual model for teacher team learning with a focus on integration of divergent perspectives by considering multiple aspects of team learning. In this section, we illustrate multilayers of teacher team learning given various frameworks, constructs, and ideas from various other areas. Specifically, in order to uncover different aspects of team learning, we employed the Dechant \& Marsick's (1993) empirical model of team learning as our central analytic lens, along with other theories and research that uncover other aspects of team learning (i.e., affective aspect, motivational aspect, relational aspect, and other team learning conditions, such as power and leadership).

\section{An Empirical Aspect of Teacher Team Learning}

Dechant \& Marsick's (1993) Empirical Model

Dechant \& Marsick's (1993) model explains that team learning occurs through the interactive processes of thinking and action, and these processes consist of five components, including framing, reframing, experimenting, crossing boundary, and integrating perspectives as shown in Figure 1 (Dechant \& Marsick, 1993; Kasl et al, 1997).

FIGURE 1

\section{AN EMPIRICAL MODEL OF GROUP LEARNING}

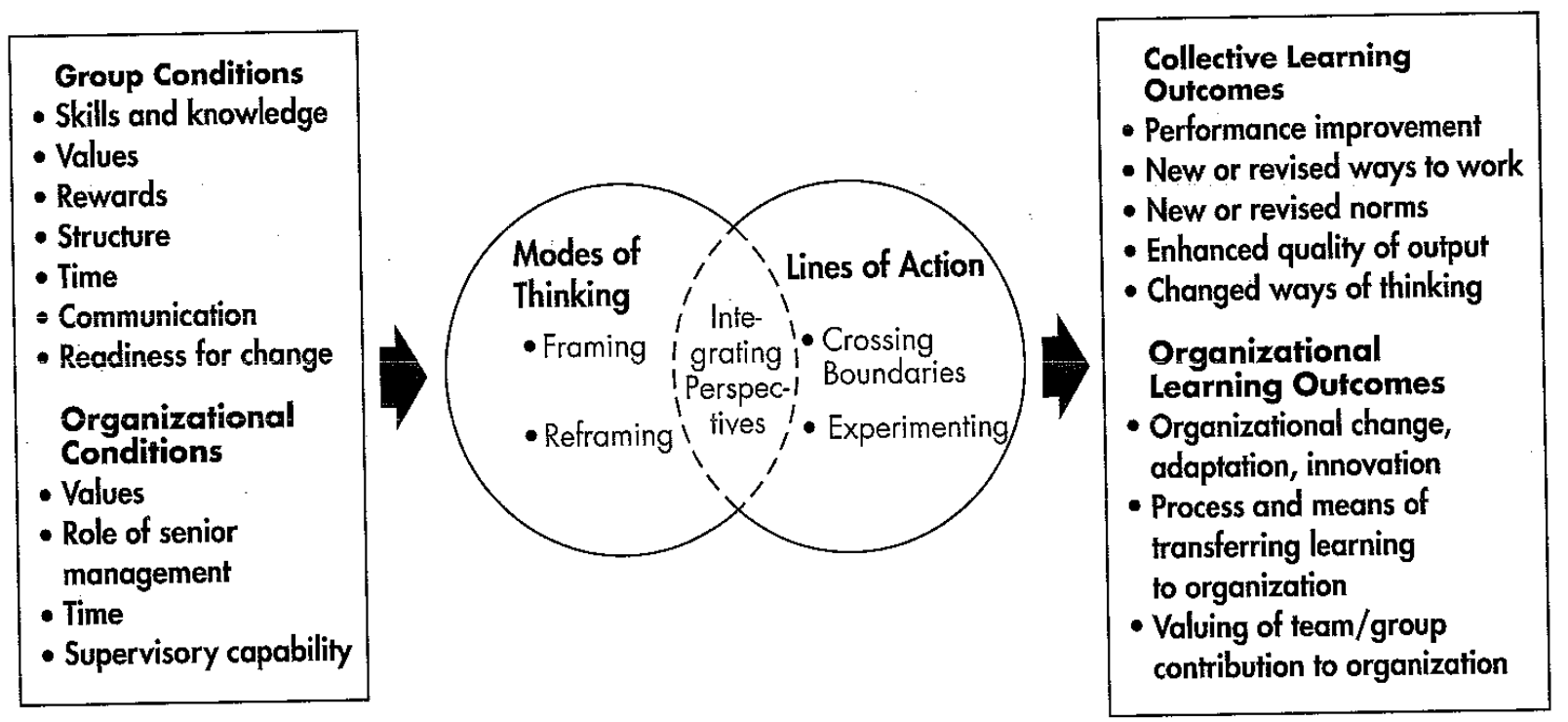

Reprinted from Team Learning Survey (p. 3), by K. Dechant \& V. Marsick, 1993, Organization Design and Development, Inc. 
Thinking, from this perspective, includes (a) framing, in which members have initial views on an issue, situation, person, or object, given past understanding and present input, and (b) reframing, in which members transform their initial perception into a new understanding or frame "as a result of incorporating new facts or knowledge" (Kasl et al, 1997, p. 230). This new input comes from the process of action, including experimenting and crossing boundaries (Dechant \& Marsick, 1993; Kasl et al, 1997). During experimenting, team members test hypotheses or move through systematic and scientific ways or even trial and error, and while crossing boundaries, members interact with other individuals or units to ask for help and/or seek or exchange information, views, and ideas; or collaborate with individuals inside or outside the group to accomplish tasks (Dechant \& Marsick, 1993; Kasl et al, 1997). In the synthesis process that links thinking and action, "divergent views and new input gleaned from experimenting and crossing boundaries are reflected upon by means of team discussion, conflicts are resolved, and consensus is obtained around an issue, perception, or perspective" (Dechant \& Marsick, 1993, p. 7).

Team conditions (i.e., skills, knowledge, values, rewards, structure, time, communication, and readiness for change) and organizational conditions (i.e., values, role of senior management, time, and supervisory capability) foster or hinder these learning processes differently at every step along the way (Dechant \& Marsick, 1993; Kasl et al, 1997). Moreover, the team learning process produces not only a collective learning outcome at the team level, including "performance improvement, new or revised ways to work, new or revised norms, enhanced quality of output, and changed ways of thinking" (Dechant \& Marsick, 1993, p.3), but also organizational learning outcomes, including "organizational changes, adaptation, innovation, process and means of transferring learning to organization, and valuing of team/group contribution to organization" (Dechant \& Marsick, 1993, p. 3).

\section{Teacher Team Empirical Learning Processes}

From the perspective of Dechant \& Marsick's (1993) model, teacher teams engage in the processes of thinking and action, including framing, reframing, experimenting, crossing boundaries, and integrating perspectives. Specifically, in the modes of thinking, a teacher team initially constructs shared perceptions around educational activities (e.g., curriculum, classroom instructions, classroom management, or joint activities and tasks) and issues (e.g., events that teachers experience while teaching students, pupils, or education policies) and reframes them as a result of including new input (e.g., new knowledge or information). In a study that investigated a teacher team's learning process, Ohlsson (2013) offers a good example for how these modes of thinking manifest in practice. In one teacher team in the study, when a teacher complained about his/her student, who interrupted his/her lessons, the team initially viewed the student as the problem source and co-constructed meanings to understand in what ways they would punish the student (Ohlsson, 2013). However, in a later meeting, after one teacher introduced a new (alternative) perspective that attributed the problem to their competence as a teacher rather than the student's personality, the team worked together to reframe their approach to resolving the issue and decided to focus on how to improve their teaching and learning in order to deal with the student more effectively (Ohlsson, 2013).

In the lines of action, a teacher team seeks information, ideas, perspectives, or supports, collaborates with others to complete tasks, and experiments with their shared understanding (a) jointly in the same contexts or (b) separately in different contexts (e.g., their own classes). For instance, in their book, Transforming teamwork: Cultivating Collaborative Cultures, which explores ways of transforming teams and teamwork in schools, Zimmerman and colleagues (2019) illustrate a good example of how a teacher team demonstrates the lines of action while working on joint tasks in the same context. Specifically, while reflecting on their writing instruction by looking at students writing, a tenth grade teacher team learned that the pre-writing activities in certain content areas had a positive influence on the quality of student writing (Zimmerman et al, 2019). This new understanding that the tenth grade teacher team achieved led the team to (a) revise their writing program in the ways that changed how writing instruction was introduced and incorporated more prewriting skills and (b) implement the completely reorganized writing program subsequently (Zimmerman et al, 2019). Implementation of the new writing program was successful, and the teachers appreciated that their collective learning experience was helpful for them to teach students writing in more interesting ways, especially since none of the teachers had any pervious training in writing 
instruction (Zimmerman et al, 2019). In this example, the teacher team conducted the experiment of revising their writing program and implementing it after framing their understanding around ways of improving student writing skills, which was developed during reflection. Furthermore, after experimenting, the team reframed their initial understanding around ways of professional learning in their writing instruction. In other words, the teachers viewed training as an important means of their professional learning initially, but they started to consider team action learning as an effective way to improve their practice.

Some studies on teacher teams and team learning further suggest specific learning actions that teacher teams can take while learning on joint tasks in the same context. For example, in the study that explored the process of team learning in secondary schools by interviewing six teacher teams in five schools, Leithwood and colleagues (1997) suggested a comprehensive set of learning actions that three effective teacher teams engaged when resolving shared problems. The learning actions include (a) consulting with other people, (b) gathering information, (c) discussing and brainstorming with each other, (d) deciding on the best solution among various alternatives, (e) testing their resolution by implementing it, (f) monitoring the progress of solutions, and (g) reflecting on it (Leithwood et al, 1997). Additionally, in the study that analyzed how teacher team learning was connected to competence-based education, Wijnia and colleagues (2016) identified that during team learning, team members engaged in various activities that were conducted at the individual level (i.e., information acquisition and boundary crossing) and the collective level (i.e., information processing, storage, and retrieval). Among the learning activities, especially information storage and retrieval-which refer to the actions of "storing and re-using shared information, reached consensus, plans, and procedures" (p.117) — helped members to reach agreement in teams (Wijnia et al, 2016). The studies discussed above demonstrate that while crossing boundaries, teacher teams worked with others through consulting, brainstorming, discussing, decision-making, information seeking, information processing, and information storage and retrieval, and while experimenting, teacher teams implemented their shared understanding that was embedded in the plans and monitored the team processes and performance.

Meanwhile, some scholars maintain that teacher team members may conduct the line of action-in particular experimenting — individually, while undergoing the mode of thinking —including framing and reframing - together. For instance, when introducing his pioneer idea of contrived collegiality that still offers in-depth insight into teacher collaboration, Hargreaves (2000) describes the work of teachers and teacher collaboration at the classroom level by borrowing Huberman (1990)'s metaphor of a sculptor. Specifically, Hurberman (1990) illustrates the nature of a sculptor's work in the way that sculptors often observe each other's artwork to discuss and exchange ideas about sculpting with their fellow sculptors, but they rarely sculpt with their colleagues on the same piece of marble (as cited in Hargreaves, 2000). Indeed, many teachers are still physically separated when teaching students, and have their own individual contexts (e.g., classrooms) (Lortie, 2002). And, each member of the teacher team may carry out the experimentation of shared understanding that they achieve with their peers together by accommodating local and contextual variations in his/her own context because some of issues that teachers deal with in their classrooms are grounded in myriad contextual factors that are subtly intertwined with each other and change over time because of the people who are involved and dynamics that they create (Eisner, 1998; Hur, 2008; Lee et al, 2012).

Here, thinking and action in team learning are neither discrete processes nor activities, rather they occur simultaneously. In schools, especially in the context of professional learning, this action part of team learning is equally as important as the thinking part (Zimmerman et al, 2019). This is because the knowledge achieved becomes more robust and nuanced while teams are putting it in action, and the action makes differences for professional practice (Zimmerman et al, 2019). Indeed, many frameworks that discovered teacher team learning processes encompass both the thinking and action part of team learning. For instance, Sheard and Sharples (2016) identified five-stage processes of achieving shared understanding and capacity of working together, including (a) "questioning, criticizing or rejecting some aspects of the accepted practice and existing wisdom" (p. 674), (b) "analyzing the situation, involving mental, discursive or practical transformation of the situation in order to find out causes or explanations" (p. 674), (c) "constructing an explicit, simplified model [or concept] of the new idea that explains and offers a solution 
to the problem" (p. 674), (d) "running and experimenting with the model to understand its potential and limitations" (p. 674), (e) "implementing the model, program or strategy" (p. 674), and (f) "reflecting, evaluating and consolidating outcomes into a new stable form of practice" (p. 674). Sheard and Sharples' (2016) learning processes here involve both the thinking mode (e.g., constructing a model in the third stage) and the action mode (e.g., running and experimenting with the model in the fourth stage).

Finally, in the process of integrating perspectives, teacher team members integrate their divergent and different views, and apparent conflicts are negotiated and/or addressed "through dialectical thinking, not compromise or majority rule" (Dechant \& Marsick, 1993, p. 7).

\section{Teacher Team Learning Conditions and Outcomes}

Team conditions (e.g., structure of team learning) and organizational conditions (e.g., shared belief and culture, administrator's leadership) promote or curb the teacher team learning process at any given moment. For instance, Levine and Marcus (2010) argue that the structure and foci of collaborative activities create different learning opportunities. In their study that conducted a multi-level case study with nine teachers at a high school level, instruction-focused protocol-guided meetings led teachers to focus more on classroom management and pedagogy, while instruction-focused strongly structured meetings led teachers to more pay attention to pedagogy and methods of assessment (Levine \& Marcus, 2010). Additionally, studentfocused loosely structured meetings led teachers to highlight relationships with students and relationships with parents (Levine \& Marcus, 2010). However, none of these types helped teachers to explore academic content or knowledge in specific subjects that needed to be addressed by teachers who worked in interdisciplinary teams (Levine \& Marcus, 2010). According to Levine and Marcus (2010), the reason why the structures and foci of collaborative activities impact what teachers learn is that they differentiate not only the aspects of classroom practice that teachers want or do not want to share, but also the degree of detail that teachers allow their peers to see (Lave \& Wenger, 1991; Levine \& Marcus, 2010). This ultimately shapes collective learning opportunities for teachers by allowing their peers to decide whether or not to fully grasp the nature of each other's classroom practice and make authentic meanings of them (Lave \& Wenger, 1991; Levine \& Marcus, 2010). Furthermore, Leithwood and colleagues (1997) maintain that organizational conditions, including shared belief and culture of staff support and school growth, have a positive influence, but lack of resources and teacher burnout have negative impacts on the team learning process. In addition to the organizational conditions that Leithwood and colleagues suggest, Hargreaves $(2000,2019)$ explains that contrived collegiality, which is administratively contrived to make teachers work together to implement curriculum and instructional methods developed by others, influences teacher collaboration, including team learning, in harmful ways by decreasing teachers' motivation to engage in collaboration.

The team learning process yields both team-level and organizational-level outcomes. Many studies have investigated the benefits of teacher collaboration, including teacher team learning and teamwork, and found that positive outcomes of teacher collaboration are situated at both (a) a team level (e.g., changed patterns of action such as an increase in communication; increased knowledge/skills/understanding; individual member capacity such as improvement of teaching) and (b) an organizational level (e.g., a positive influence on school climate and culture and improvement of students' performance and achievement) (Bouwmans et al, 2017; Cherkowski \& Schnellert, 2018; Egodawatte et al, 2011; Moolenaar, 2010; Vangrieken et al, 2015).

\section{Implications From Dechant and Marsick's (1993) Empirical Learning Model}

Dechant and Marsick's (1993) model provides a helpful analytic lens to understand teacher team learning - in which different members develop shared understanding and capacity through integration of divergent perspectives - by considering multiple aspects of team learning. Specifically, Dechant and Marsick's (1993) suggests that members integrate different perspectives to achieve shared understanding and capabilities by combining with (a) the thinking process of co-constructing and transforming ideas/perceptions/perspectives at both the individual and team level, and (b) the action process of experimenting with shared ideas in joint contexts or independent contexts, and encountering and working 
with divergent others to seek, exchange, and/or store divergent information, ideas, perspectives, and supports, and accomplish tasks. Furthermore, team/organizational conditions influence the learning processes to integrate a diversity of perspectives (e.g., promoting/hindering opportunities that help members to fully understand others' practice and different contexts) (Dechant \& Marsick, 1993).

Nevertheless, employing Dechant and Marsick's (1993) model solely still limits our understanding of multi-layers of teacher team learning because the model lacks explanations of the affective and motivational dimension of team learning, relational aspects that mediate learning processes, and other conditions that influence learning process (e.g., power, team leader's leadership). These are important aspects of team learning that we need to look at (Alderfer, 2011; Edmondson \& Harvey, 2018; Fleming, 2014; Yorks \& Kasl, 2002; Wells, 1995). In other words, important questions still remain: (a) In what ways are different and divergent teachers motivated to participate in team learning? (b) What roles do feelings play in the learning process of integrating diversity of perspectives to achieve share understanding? (c) In what ways do different members actually interact and relate with each other while developing a shared understanding and capacity through integrative ways, not by a majority rule or compromise (e.g., what types of dialogue they engage in)? (d) In what ways does power related to majority voices, professional authority, or positional authority have an influence on the team learning processes? (e) In what ways do team leaders (i.e., head teachers, informal leaders) impact team dynamics?

No one lens or framework can offer insight into all aspects of teaming and team learning and therefore it is essential to bring frameworks together. Given the limitations of the Dechant and Marsick's (1993) model, we also explore various research and theories - which can reveal the affective, motivational, and relational aspects of team learning and other team learning conditions that our central analytic lens does not cover, but are necessary to gain more in-depth understanding of teachers' team learning.

\section{Affective Aspect of Team Learning}

From the view of pragmatism that had dominant currency previously, only cognition was considered as our meaning-making system, but nowadays, many alternative frameworks (e.g., feminism, phenomenology) that support the idea of multiple ways of knowing have shed light on affection as one of important ways of making sense of our experience and world (Eisner, 1998; Lloyd-Zannini, 1998; Yorks \& Kasl, 2002, 2012; Taylor, 1994). For instance, according to Heron (1992), we have four ways of knowing, including experiential, presentational, propositional, and practical way of knowing (Yorks \& Kasl, 2002, 2012). All methods of knowing have their own validity, but given an up-hierarchical relationship, the validity of all other higher layers of ways of knowing are grounded in the experiential way of knowing that is located at the bottom of the pyramid (Heron, 1992; Kasl \& Yorks, 2016). Experiential way of knowing occurs when people encounter and feel things, such as energy, person, process, or entity, and in order to share this experiential way of knowing, empathic field is a precondition (Heron, 1992; Kasl \& Yorks, 2016; Yorks \& Kasl, 2002, 2012). However, establishing such empathic field is not easy due to the paradox of diversity (Yorks \& Kasl, 2002, 2012; Kasl \& Yorks, 2016). In other words, people who share a common experience and background often create an empathic field without conscious effort as they can understand each other's words in the context of the similar felt experience easily (Yorks \& Kasl, 2002, 2012). On the other hand, it is difficult and insufficient to people who are very different from each other to share each other's felt experience only through words (Yorks \& Kasl, 2002, 2012).

Here, Yorks and Kasl (2002) argue that the presentational knowing, which is "evident in our intuitive grasp of the significance of imaginal patterns as expressed in graphic, plastic, moving, musical, and verbal art forms" (p. 182), can play a pivotal role in creating the empathic field. Specifically, presentational knowing leads people to bring felt experience into conscious awareness by being aware of their emotion through the expressive process (Yorks \& Kasl, 2002, 2012; Kasl \& Yorks, 2016). With increased awareness of their felt experience, people are more capable of aligning their affective states with their conceptual sense-making, and hence participate in more meaningful prepositional knowing, the mode of discourse (Yorks \& Kasl, 2002, 2012). This process of awareness of felt experience and making congruence between affective mode and conceptual mode establishes the empathic field with different others more easily by 
making it easier for people to communicate and glimpse into each other's felt experiences (Kasl \& Yorks, 2016).

The idea of empathic field and the idea of presentational knowing that illuminate the affective aspect of collective learning can also give us a deeper insight into teacher team learning, whereby teachers integrate divergent perspectives to develop shared understanding and capacity. For example, the Waldorf schools which value art as one of the ways of making meaning of their experience recommend teachers and teacher teams to incorporate various art forms, including imaginal, moving, and musical symbols, into all meeting structures as shown in the following two examples (Mitchell, 1992). This is because the Waldorf school members believe that communicating with different others only through rational words can result in destructive conflicts and tensions coming from misunderstanding and hurt feelings, but art form (i.e., presentational knowing) can alleviate them by creating feelings of empathy, which connects them to better understanding of each other's different experiences (Choi, 2014).

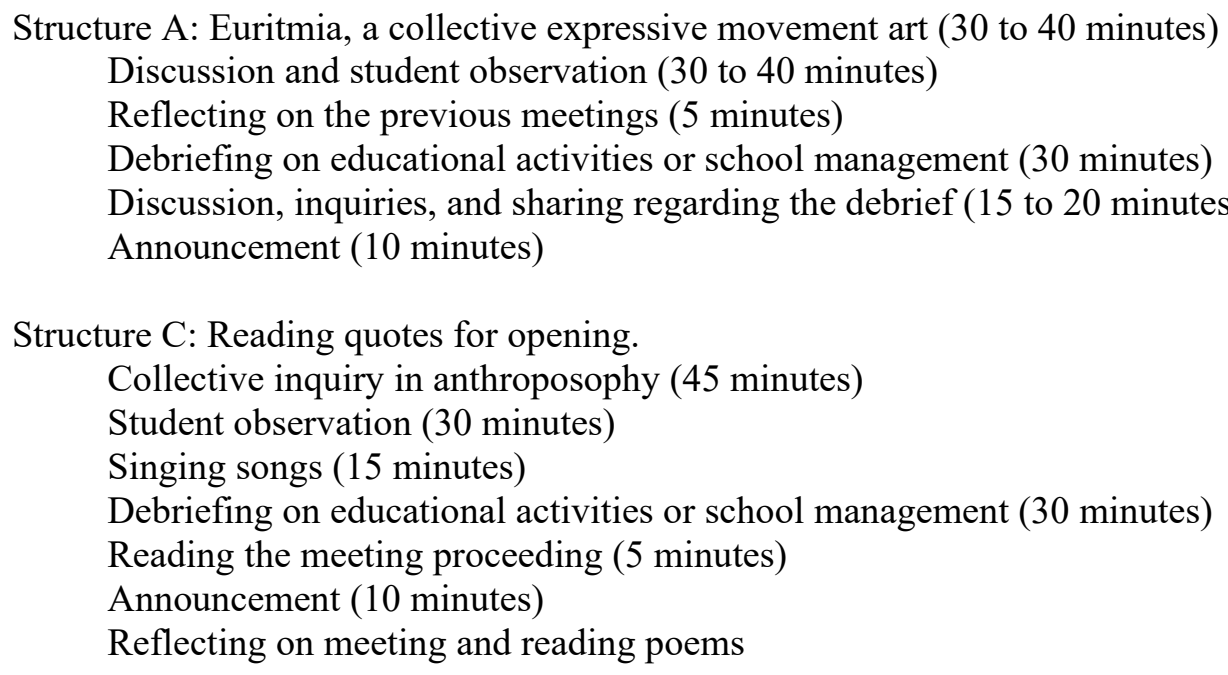

In sum, although creating an empathic field is a crucial task when teacher teams learn together and integrate their different and divergent perspectives around curriculum and educational activities, creating such a field is challenging. Presentational learning that is manifested in art form can play important roles, as presentational knowing helps teachers to share each other's different felt experience more meaningfully. In other words, by incorporating presentational knowing into the team learning, teacher teams can create empathic fields that lead members to understand and share each other's different experiences effectively and thus be able to engage in meaningful discourse with different others.

\section{Motivational Aspect of Team Learning}

Motivation that leads different individuals to keep moving toward shared directions jointly is the crucial layer of team learning, and Bandura's theory of collective efficacy and Edmonson's idea of recognition give us in-depth insight into the motivational aspect of teacher team learning. Specifically, Edmondson (2012) explains that teaming that consists of team working and team learning starts with recognition. Recognition here refers to a process in which people realize their interdependence with others in order to accomplish whole works (Edmondson, 2012). This idea of recognition can help us understand how to encourage individual teachers with divergent beliefs and contexts to learn from their colleagues' different perspectives and integrate them in the meaningful ways. Specifically, Eisner $(1998,2004)$ argues that teachers need each other even for problems happening in their own classes. This is because serious problems in classrooms are not due to issues that teachers necessarily already know about, and hence he/she must make efforts to understand and resolve them (Eisner, 1998, 2004). Rather, those are the problems, which the teacher lives in and thus they cannot be aware of by themselves (Eisner, 1998, 2004). As these problems can be identified by others' different perspectives, teachers would benefit from professional collaboration 
with other teachers (Eisner, 1998, 2004). By recognizing this interdependent nature of teaching jobs to accomplish the ultimate educational goal of serving students' wellbeing and achievement, teachers may want to step into team learning and share different ideas and perspectives with their colleagues, and incorporate them into their professional practice.

While Edmondson (2012) explains how people start to join in collaboration, Bandura (2001) describes what leads people to keep working and learning together by suggesting the construct of collective efficacy. Specifically, in the conceptual study that suggests the construct of collective agency, Bandura (2001) refers to collective agency as socially interdependent efforts that people make in coordination with others to achieve what they cannot accomplish individually. According to Bandura (2001), the heart of collective agency is collective efficacy, shared belief of we can do it, which leads a collection of people to keep moving towards achieving a desired outcome. In the area of education, many researchers have tested and refined collective efficacy and revealed that collective agency contributes to promoting effective teacher teaming and team learning (Adams \& Forsyth, 2006; Donohoo et al, 2018; Goddard et al, 2004). Specifically, in the study that explored four inclusive schools that demonstrated successful teacher teaming, Lyons and colleagues' study (2016) found consistent characteristics of teacher teams across these four different schools (Lyons et al, 2016). One of them was the strong belief in "their ability to successfully work through problems and develop solutions together" (Lyons et al, 2016, p. 903). And, the teachers' beliefs about their collective efficacy was the most salient in teachers' discussions of their teaching and learning practices, and practices to change student behaviors (Lyons et al, 2016). Interestingly, teachers' collective efficacy contributed to their effective teamwork and team learning, but participating in team collaboration also promoted teachers' collective efficacy reversely (Lyons et al, 2016). Goddard and colleagues (2004)'s discussion also supports these findings of Lyons and colleagues' (2016) study as they argue that teacher's collective efficacy is mostly presented with regard to their collective capacity to make positive impacts on students, and teachers have higher collective efficacy by being involved in collaborative work (Kurz \& Knight, 2003; Moolenaar et al, 2012).

In sum, teachers who have different background and context from each other, and hence may be reluctant to collaborate with other teachers can continuously be involved in team learning, and integrate different perspectives to accomplish shared understanding and capacity around their practice through a process of being aware of the interdependent nature of their work, as well as having collective efficacy of believing we can make contributions to student learning. Additionally, collective efficacy is a shared belief among members, which is a driving force for them to continue their collective learning and working, but reversely, by participating in team learning and working, teachers can have the stronger shared belief of collective efficacy.

\section{Relational Aspect of Team Learning}

Team life is more or less than the sum of individual members due to the group dynamics, which are the patterns of relation and interaction that the members co-create while working and learning together (Watkins \& Marsick, 2010; Wells, 1995). In other words, the patterns of interaction among team members and its transformation in joint social practice can be considered to be an important dimension of team learning (Havnes, 2009). In this subsection, by looking into the various disciplinary areas, including micropolitical, socio-psychological, sociocultural, social-historical, and sociolinguistic perspectives, we explore the interactive and relational aspect of teacher team learning along with the three constructs of (a) conflicts, (b) recognition, and (c) team conversation (team-talk). Along with these three constructs, we look at what interactive and relational patterns teachers engage in the process that teacher teams develop shared understanding and team capacity through integration of divergent perspectives.

\section{Conflicts}

Many discussions, including those from a micro-political perspective and adult learning, have imposed great emphasis on the important role of conflicts in teacher collaboration (Achinstein, 2002; Edmodnson, 2002; Zimmerman et al, 2019). This is due to the fact that conflicts provide team members with opportunities to have critical reflection (Achinstein, 2002; Edmonson, 2002; Zimmerman et al, 2019). In 
other words, team members can challenge each other's viewpoints and taken-for-granted assumptions of their practice and consider more promising alternatives to change and improvement (Achinstein, 2002; Decuyper et al, 2010; Mezirow, 2003; Zimmerman et al, 2019).

Conflict is an ongoing social interaction process-whereby individuals and groups clash and negotiate each other's differences in beliefs, ideas, and actions and each other's boundaries in terms of autonomy, authority, and power, when their divergent (to some degree incompatible) views, goals, actions, and interests are exposed (Ball, 1987). For example, in Havnes (2009)'s research, when co-constructing their shared object and scripts, interdisciplinary teacher teams underwent ongoing processes of negotiation and renegotiation in terms of not only their beliefs, ideas, and actions regarding their shared tasks (e.g., the project theme and its boundary, the principle of teaching methods and its application, and specific plans, such as teacher materials), but also each other's boundaries regarding their autonomy and authority (e.g., each teacher's role, boundaries between subjects). Havnes (2009) argued that the starting point of these team discussions of ongoing negotiation was the diversity derived from each participant's expertise.

Nevertheless, as many studies explained, the majority of teacher teams tend to prevent conflicts within a team (Achinstein, 2002; Ohlsson 2013; Sharon \& Karen, 1997; Troen \& Boles, 2012; Vangrieken et al, 2016). Specifically, teachers tend to care about other's views and pursue harmony within a team (Troen \& Boles, 2012). Hence, teacher teams easily step into the area of group thinking that leads members to impose pressure not to express opinions that go against any of the team's view and censor themselves so that they can reach consensus easily (Janis, 2008; Troen \& Boles, 2012). For instance, in Sharon and Karen's (1997) research, members in teacher teams had great commitment to teaming, making an effort to openly challenge and critique each other during teaming in order to develop their community further; however, in actual practice, they dealt with issues that they could agree upon easily and tended to avoid problems that caused grave conflicts or needed critical reflection. Conflicts between and within teams simmered under the surface without being effectively resolved (Sharon \& Karen, 1997).

In response to the teacher team's tendency of conflict avoidance, Edmondson (2012) developed team psychological safety that refers to "the climate that takes shape as a consequence of two factors - the frames and behaviors of local leaders and the daily behaviors and interactions among peers working together" (p. 124). Furthermore, Edmonson (2012) also suggested team interactive behaviors that contribute to creating team psychological safety, including speaking up, collaborating, experimenting, and reflecting (Edmonson, 2012; Knapp, 2010). Given the idea of team psychological safety, building the patterns of interaction that generate such safety during team learning helps teachers to be more willing to engage themselves in conflicts whereby members offer different ideas and views, and question, challenge, and disagree with each other's perspectives (Edmonson, 2012; Harvey et al, 2019; Vangrieken et al, 2016).

Meanwhile, some scholars point out that conflicts are not always constructive to teams, which means that a certain type of conflict can weaken the team capacity to work and learn together (Garmston \& Wellman, 2016; Zimmerman et al, 2019). Specifically, while cognitive conflict - which is also called task conflict - "supports teams in problem solving, goal setting, decision-making, and collaborative learning" (p.91), relationship conflict - which is also referred to as affective, emotional or social conflict and usually appears at the interpersonal level — can activate emotions, such as "mistrust, anger, fear, anxiety, resistance and resentment" (p.91), and create hostile and unsupportive rifts in a team (Zimmerman et al, 2019). Therefore, in the idea of conflict consciousness, Zimmerman and colleagues (2019) suggest being aware of these two types of conflict and managing them differently. For instance, team members can create open spaces to (a) discuss divergent and different ideas and perspectives for cognitive conflicts, but (b) communicate relationship conflicts directly and promptly as they occur (Zimmerman et al, 2019).

In summary, during team learning, teacher team members can integrate their different and divergent perspectives by engaging in the process - in which members co-create continuous interaction patterns of (re)negotiation to reach agreed upon understandings regarding (a) shared tasks and problems and (b) each other's boundaries regarding autonomy, authority, and power in the presence of team psychology safety and conflict awareness. 


\section{Recognition}

Many studies from the socio-psychological perspective argue that depending on the identity groups each team member represent (e.g., race/ethnicity, gender, social class, nationality) and the stereotypic attributions ascribed to the identity groups by other individuals and community, members can be assigned to different roles (e.g., leader, follower) within a team through the shared unconscious interaction patterns among the members (Brazaitis, 2014; Bion, 1961; McRae \& Short 2010; Wells, 1995). Furthermore, in some cases, team members even form tacit interactions of excessive projective identification toward a certain member (or members) based on his/her identity group - especially those in an identity group that brings the member a disadvantage rather than one which brings him/her privilege - and collude to place $\mathrm{him} /$ her in destructive roles, such as a scapegoat (Holvino, 2012; McRae \& Short 2010; Wells, 1995).

As opposed to the destructive tacit dynamic pattern that members may co-construct to exclude a certain member(s) and ignore what he/she can possibly contribute to the team, the idea of recognition presents relational and interactive patterns that help team members who have different backgrounds to avoid such destructive unconscious interaction patterns and integrate their diversity in meaningful ways. Specifically, West and colleagues (2016) explored how non-traditional learners with disadvantaged educational and social capital nonetheless transformed their identities, and survived and prospered through higher education in England and the Republic of Ireland. In this article, West and colleagues (2016) revealed that Bourdieu's ideas of habitus, dispositions, and capital had limitations in the way of neglecting psychological or experiential capital. In light of this, West and colleagues (2016) tried to fill in the gap by incorporating a psychosocial analysis of Winnicott and Honneth. In other words, West and colleagues (2016) attempted to attest that "equality, identity, autonomy, freedom and self-realization can only be achieved intersubjectively through a process of being recognized by significant others" (p.131). Particularly, West and colleagues (2016) highlighted the importance of self-esteem-which people can achieve through the experience of being recognized by a community for contributions-in the context of higher education.

Given West and colleagues' (2016) discussion on recognition, teacher teams can forms relational patterns by having interactions of recognizing different others' contributions, rights, and caring in respectful and inclusive ways while engaging team learning. And, this allows each member to have an identity, autonomy, freedom, and a role to make contributions to the team, without simply excluding some (or a few) of the members-particularly members who have identity groups that are considered to bring them a disadvantage.

\section{Team Conversation (Team-Talk)}

The symbol (e.g., language) mediates interaction (Engeström, 2008; Mead \& Morris, 1934), and the form of symbol shapes meanings that we make around our experience and the world (Cassirer, 1944). This implies that conversations that merely consist of symbols, especially language, are an essential part of understanding the interactive aspect of team learning. In other word, it is important to look at discursive patterns that teacher teams engage to foster integration of divergent perspectives during team learning since shared understanding that team members co-construct and ways of achieving such integrated understanding are inseparable (Engeström, 1994; Havnes, 2009; Kegan \& Lahey, 2001).

In light of this, many researchers have explored discursive patterns that occurred during group/team learning. For instance, Schapiro and colleagues (2012) show us different forms of dialogue that group members partake in depending on the types of transformative learning. In other words, Schapiro and colleagues (2012) revealed that transformative learning can be categorized into three groups in terms of the developmental outcome that they aim for, and group dialogues vary depending on these types of transformative groups. Specifically, the group of personal growth and self-awareness usually engages in dialogues of listening, witnessing, or offering feedback (Schapiro et al, 2012). The group of relational empathy across differences involves storytelling, in which each person reveals different aspects of stories and construct their own social identities in relation to others by reflecting on the different aspects of each other's stories (Schapiro et al, 2012). The group of critical systemic consciousness involves dialogues of collaborative inquiries, in which people develop a deeper understanding of the structural and systemic limitations to reaching full humanization and empowerment (Schapiro et al, 2012). 
Some studies on teacher teams also have investigated discursive patterns that team members engaged during team learning. For instance, in the research that explored team-talk of two interdisciplinary teacher teams in two different schools in Norway, Havnes (2009) identified four patterns of teacher-talk that shaped opportunities for team learning and development. These patterns of interaction include: (a) preserving individualism, whereby teachers renegotiate personal autonomy, responsibility, and boundaries; (b) coordination, in which teachers assure coordination of their interrelatedness and division of labor; (c) cooperation, whereby teachers create shared objects or enterprise; and (d) sharing (conversation), where teachers clarify pedagogical motives (Havnes, 2009). Furthermore, Havnes (2009) revealed that a certain discursive type is more likely to promote teacher team learning. In other words, as opposed to the teacher team whereby the discursive pattern of coordination was dominant, the teacher team in which the pattern of cooperation and conversation were dominant displayed "a collegial, teaching-oriented 'we-ness' in the team-talk" (Havnes, 2009, p. 171). In addition to Havnes' (2009) research, many studies in the area of education have revealed that storytelling as the natural form of sense making and communicating further (a) creates connection and empathy and (b) moves a collection of different people together (Ganley, 2010; Maslin-Ostrowski et al, 2018; Tyler \& Swartz, 2012).

In sum, as shown in the above research, "team-talk represents a series of moments in a flow of social practice" (Havnes, 2009, p. 170), and the form of conversation constitutes, molds, and facilitates the shared understanding that teacher teams achieve (Engeström, 2008; Havnes, 2009). In light of this, the certain forms of team conversation, such as storytelling, cooperation, and sharing, enhance collegial, teachingoriented, social practices within teams and help teacher teams to integrate the differences within teams further.

\section{Other Team Conditions That Influence Learning Processes: Power and Leadership}

Activity theory and Edmondson's work (2012) of teaming suggest power and leadership as essential team learning conditions, which have great impacts on teacher team learning process as well as learning outcome. Specifically, Engestöm's activity theory provides a useful analytic lens to interpret collective aspects of human activity by suggesting constructs of systemic factors (Engeström, 2008). Systemic factors that include division of labor, community, and rules are a macro-level of activity that influence a micro process, in which subject manages the object with instruments in order to achieve a desired outcome (Engeström, 2008; Youn \& Park, 2012). Here, division of labor, one of the systemic factors, refers to both horizontal and vertical relationships among members coming from power and authority (Engeström, 2008; Youn \& Park, 2012). Considering learning as the activity from the perspective of activity theory, power can be an important condition that hinders or fosters the team learning process. Mezirow (2003) also pointed out that power relationships can distort the validity of outcome (mutual agreement) of conversation learning, and "hence is a major concern of adult educators" (p. 61). There are various kinds of power relationships within a teacher team. A majority voice has more power than a minority opinion, and teachers who have more professional authority (more experience, more knowledge, higher degrees) or are in higher positions have more power than ones who do not (Jin et al, 2015; Bush, 2011). These power relationships may distort team learning processes and outcomes.

Furthermore, Edmondson (2012) highlights the important role of leadership in team dynamics. Specifically, Edmondson (2012) argued that teaming requires team leadership that creates hospitable conditions for teaming and helps teams to build shared understanding and coordinate actions. Therefore, Edmondson (2012) suggested various team leadership actions that promote teaming, including framing the situation for learning, making it psychologically safe to team, learning to learn from failure, and spanning occupational and cultural boundaries. Teacher teams have formal leaders (i.e., head teachers), informal leaders, or even shared leadership among members (Spillane \& Healey, 2010), and hence the leadership actions that Edmondson (2012) suggested can facilitate teaming by creating positive group dynamics. 


\section{DEVELOPING A CONCEPTUAL FRAMEWORK FOR TEACHER TEAM LEARNING}

The purpose of this study was to build a comprehensive model for teacher team learning with focus on integration of divergent perspectives by considering multiple dimensions of teacher team learning. In previous sections, we explored multilayers of teacher team learning, including (a) the experiential aspect that highlights both cognition and action, both experiential learning and transformative learning, both team level and organizational level, and both learning condition, process and outcome, (b) the affective aspect, (c) the motivational aspect, (d) the relational and interactive aspect, and (e) additional team learning conditions. In this section, we attempt to synthesize our discussions in the previous sections into a coherent framework.

\section{FIGURE 2}

\section{A CONCEPTUAL MODEL FOR TEACHER TEAM LEARNING}

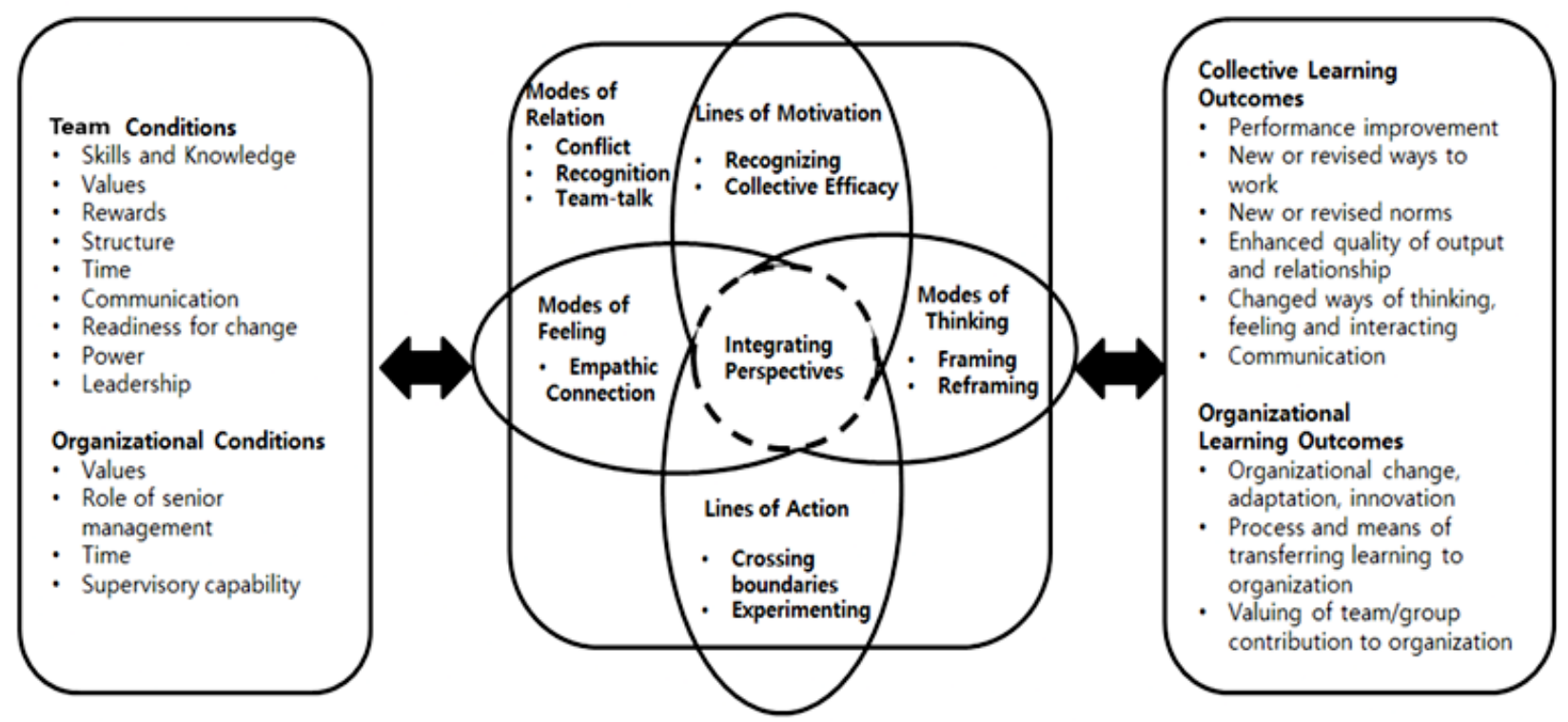

As shown in Figure 2, during team learning, teacher teams engage in various processes. Specifically, the thinking process involves the process of framing initial shared perceptions and reframing them. The feeling process involves the process of creating an empathic field-where members share and understand each other's different experience in more effective and meaningful ways - through presentational knowing. The process of motivating to participate in team learning involves the process of being aware of interrelatedness with different others and having the collective belief of we can make contributions to student achievements. The relational process involves (a) the conflict burdened process of (re)negotiating regarding differences in beliefs and actions and each other's boundaries in the presence of psychological safety and conflict consciousness, (b) the inclusive and respectful process of recognizing different others and perspectives, and (c) the discursive process of engaging various types of team-talk that include diversity of perspectives in teams. The acting process includes the process of crossing boundaries by working with divergent others, who are inside or outside teams, and experimenting with shared understanding in shared and/or independent contexts. Lastly, teacher teams undergo the synthesis process that links thinking, feeling, interacting, and acting across divergent and different perspectives. This is the process of integrating perspectives, in which teachers come to understand each other's different views and emotions and synthesize them so that apparent conflicts are negotiated and addressed through dialectical thinking and empathic connection in inclusive and negotiated conversation and interactions. 
All of the learning processes are interrelated, but in particular, without engaging in other learning processes that highlight different aspects of team learning (i.e., cognitive, affective, motivational and relational/interactive processes) with balance, it is challenging for teacher teams to undergo this integrative process effectively and meaningfully. For example, in cases where teacher teams only focus on the cognitive mode of team learning (i.e., framing and reframing), members may not engage in meaningful discourse, where they share and integrate different perspectives to frame or reframe team understanding, by failing to understand and communicate each other's different perspectives that are embedded in their different felt-experience fully enough. Additionally, members may not attempt to continuously participate in the team discourse of framing and reframing by failing to recognize each other's interdependence to get their work done or losing their driving force to learn from and with others. Also, members may not be able to gain enough access to different perspectives of all members by excluding certain members' contributions and voices, refusing to share their different perspectives with others, failing to manage affective conflicts, or partaking in inappropriate form of team conversation, such as accusation. This is why we need to consider multi-layers of team learning in order to help teacher teams to engage in team learning where integration of divergent perspective is central.

Furthermore, the learning processes can be fostered or hindered by not only team conditions - such as each members' skills and knowledge, shared values, power, leadership, and/or time-but also organizational conditions - such as values, roles of senior management and leaders, and/or time. Team learning outcomes may include performance improvement, new or revised ways of working, new or revised team norms, enhanced quality of output (i.e., curriculum, educational activities), changed ways of sharing thinking and feeling regarding their teaching jobs, changed ways of interacting, and enhanced quality of relationships.

\section{CONCLUSION}

Teacher teamwork and teaming are a journey of team learning. Given the fact that teachers have different backgrounds, interests, ideas, perspectives, and contexts, team learning should be a process in which teachers integrate these different lines of diversity. Teacher teams can be helped by considering the (a) cognitive process of (re)co-constructing shared meanings, (b) the affective process of creating connecting feelings with different others, (c) the motivating process of leading a collection of different individuals to collaborate and learn together, (d) the relational processes of engaging interactions that negotiate, recognize, and communicate with different others, and (e) the acting processes of experimenting with their shared understanding and working with divergent others. Furthermore, it is also important to create team/organization conditions in a way that promotes team learning.

These findings can help teacher teams to include and integrate divergent perspectives in effective ways to serve students' learning and wellbeing. Schools, districts, and external professional development programs (e.g., college) can use results of this research to (a) provide principals, teacher leaders, teacher teams, and teachers with the frameworks that they can adopt to their team and learning practice, (b) coaching teacher leaders and teachers to plan for their teaming and team learning and working alongside the teacher leaders during the teaming and team learning, and (c) helping teacher team members to develop their capacity to work and learn together. More importantly, the findings can help teachers to not only listen to others more deeply and uplift their own and others' voices, but also to collaborate across lines of different kinds of diversity by integrating divergent perspectives. This has become even more important today in the midst of a triple pandemic that has encouraged the growth of social justice movements while generating more adaptive challenges (Bouffard, 2020). In other words, there is the growing attention to the need for diversity within the teaching workforce (NYSED, 2019), and school educators are further required to integrate and leverage diversity toward more inclusive, culturally responsive instruction, creating novel approaches to address the complex challenges that they face.

In addition to the contributions of the research above, we also want to highlight some limitations of our study and hope that these are useful for future research. First, this study is a conceptual paper that develops a theoretical model for teacher team learning with focus on integration of divergent perspectives by 
exploring various theories and research. Thus, more empirical studies, such as case studies, that apply the team learning model to actual teacher team practice are required. Second, it may be that for teachers as independent professionals, teacher team learning is a picture of the whole and key principles governing the whole, with recognition that contextual applications will differ because of local variations.

\section{ACKNOWLEDGEMENT}

Paper presented at the American Educational Research Association (AERA) Annual Conference, A Virtual Meeting, April 2021.

\section{REFERENCES}

Achinstein, B. (2002). Conflict amid community: The micropolitics teacher collaboration. Teachers College Record, 104(3), 421-455. https://doi.org/10.1111/1467-9620.00168

Adams, C.M., \& Forsyth, P.B. (2006). Proximate sources of collective teacher efficacy. Journal of Educational Administration, 44(6), 625-642. https://doi.org/10.1108/09578230610704828

Alderfer, C.P. (2011). The five laws of embedded intergroup relations theory. In The Practice of Organizational Diagnosis: Theory and Methods (pp. 131-169).

Bandura, A. (2001). Social cognitive theory: An agentic perspective. Annual Review of Psychology, 52, $1-26$.

Bion, W.R. (1961). Experiences in Groups. New York, Basic Books.

Bouffard, S. (2020). Learning as much as we can as fast as we can. The Learning Professional, 41(3). Oxford, OH. Learning Forward.

Brazaitis, S.J. (2014). Group relations and conflict resolution. In P.T. Coleman, M. Deutsch, \& E.C. Marcus (Eds.), The handbook of conflict resolution: Theory and practice (pp. 947-970). JosseyBass/Wiley.

Bouwmans, M., Runhaar, P., Wesselink, R., \& Mulder, M. (2017). Fostering teachers' team learning: An interplay between transformational leadership and participative decision making? Teaching and Teacher Education, 65, 71-80. https://doi.org/10.1016/j.tate.2017.03.010

Bush, T. (2011). Theories of educational leadership and management. Los Angeles: SAGE.

Cassirer, E. (1944). An Essay on Man: An Introduction to a Philosophy of Human Culture. Yale University Press.

Cherkowski, S., \& Schnellert, L. (2018). Teacher, team and school change through reciprocal learning. Teacher Development, 22(2), 229-248.

Choi, H. (2014). Conceptualizing an educational management model with focus on an artistic approach. Master thesis. Seoul National University, Seoul.

Dechant, K., \& Marsick, V.J. (1993). Team learning survey: Facilitator guide. Organization and development, Inc.

Decuyper, S., Dochy, F., \& Van den Bossche, P. (2010). Grasping the dynamic complexity of team learning: An integrative model for effective team learning in organisations. Educational Research Review, 5(2), 111-133. https://doi.org/10.1016/j.edurev. 2010.02.002

Donohoo, J., Hattie, J., \& Eells, R. (2018). The power of collective efficacy. Educational Leadership, $75(6), 41-44$.

Drach-Zahavy, A., \& Somech, A. (2001). Understanding team innovation: The role of team processes and structures. Group Dynamics: Theory, Research, and Practice, 5(2), 111-123. https://doi.org/10.1037/1089-2699.5.2.111

Drago-Severson, E. (2009). Leading adult learning. CA: Corwin Inc. \& Learning Forward.

Drago-Severson, E., O'Connor, C.J., \& Blum-DeStefano, J. (2018). When teams hit rough waters: Navigate challenges with a developmental approach. The Learning Professional, 39(4), 54-58.

Edmondson, A.C. (2012). Teaming: How organizations learn, innovate, and compete in the knowledge economy. San Francisco: Jossey-Bass. 
Edmondson, A.C., \& Harvey, J. (2018). Cross-boundary teaming for innovation: Integrating research on teams and knowledge in organizations. Human Resource Management Review, 28, 347-360.

Egodawatte, G., McDougall, D., \& Stoilescu, D. (2011). The effects of teacher collaboration in grade 9 applied mathematics. Educational Research for Policy and Practice, 10(3), 189-209. https://doi.org/10.1007/s10671-011-9104-y

Eisner, E.W. (1998). The Kinds of Schools we Need: Personal Essays. Portsmouth, NH: Heinemann.

Eisner, E.W. (2004). What can Education learn from the Arts about the practice of education? International Journal of Education \& the Arts, 5(4), 1-13.

Fleming, T. (2014). Reclaiming the emancipatory potential of adult education: Honneth's critical theory and the struggle for recognition. In $11^{\text {th }}$ International Transformative Learning Conference Proceedings. Teachers College, Columbia University.

Ganley, B. (2010). Re-weaving the community, creating the future. Storytelling at the heart and soul of healthy communities. Orton Family Foundation.

Garavan, T.N., \& McCarthy, A. (2008). Collective learning processes and human resource development. Advances in Developing Human Resources, 10(4), 451-471. https://doi.org/10.1177/1523422308320473

Garmston, R.J., \& Wellman, B.M. (2016). The adaptive school: A sourcebook for developing collaborative groups. Lanham, MD: Rowman \& Littlefield.

Goddard, R.D., Hoy, W.K., \& Hoy, A.W. (2004). Collective efficacy beliefs: Theoretical developments, empirical evidence, and future directions. Educational Researcher, 33(3), 3-13. https://doi. org/10.3102/0013189X033003003

Gregory, A. (2010). Teacher learning on problem-solving teams. Teaching and Teacher Education, 26(3), $608-615$.

Hagreaves, A. (2000). Contrived collegiality: The micropolitics of teacher collaboration. In B.J. Stephen (Ed.), Sociology of education (pp. 1480-1501). New York: Routledge.

Hargreaves, A. (2019). Teacher collaboration: 30 years of research on its nature, forms, limitations and effects, Teachers and Teaching, 25(5), 603-621.

Hargreaves, A., \& O'Connor, M.T. (2018). Collaborative professionalism: When teaching together means learning for all. A SAGE Company.

Harvey, J.F., Johnson, K.J., Roloff, K.S., \& Edmondson, A.C. (2019). From orientation to behavior: The interplay between learning orientation, open-mindedness, and psychological safety in team learning. Human Relations, 72(11), 1726-1751. https://doi.org/10.1177/0018726718817812

Holvino, E. (2012). Time, space and social justice in the age of globalization: Research and applications on the simultaneity of differences. Practising Social Change, 5, 4-11.

Hur, B. (2008). Artistic qualities of cultural leadership in educational organizations. The Journal of Educational Administration, 26(4), 489-507.

Jin. D., Lee, Y., \& Kim, J. (2018). Educational Administration and School Management. Seoul, Kyoyookbook.

Janis, I.L. (2008). Groupthink. IEEE Engineering Management Review, 36(1), 36.

Kasl, E., Marsick, V.J., \& Dechant, K. (1997). Teams as learners. Journal of Applied Behavioral Science, $33(2), 227-246$.

Kasl, E., \& Yorks, L. (2012). Learning to be what we know: The pivotal role of presentational knowing in transformative learning. In E. Taylor, P. Cranton \& associates (Eds.), The handbook of transformative learning: Theory, research and practice (pp. 503-519). Jossey-Bass.

Kasl, E., \& Yorks, L. (2016). Do I really know you? Do you really know me? Empathy amid diversity in differing learning contexts. Adult Education Quarterly, 66(1), 3-20.

Kegan, R., \& Lahey, L.L. (2001). How the way we talk can change the way we work: Seven languages for transformation. San Francisco: Jossey-Bass/Wiley.

Knapp, R. (2010). Collective (team) learning process models: A conceptual review. Human Resource Development Review, 9(3), 285-299. https://doi.org/10.1177/1534484310371449 
Kurz, T.B., \& Knight, S. (2003). An exploration of the relationship among teacher efficacy, collective teacher efficacy, and goal consensus. Learning Environments Research, 77(2), 111-128.

Lave, J., \& Wenger, E. (1991). Situated learning: Legitimate peripheral participation. Cambridge University Press.

Lee, H., Um, H., Chung, J., \& Shin, J. (2012). The metaphors of 'teaching as art' and 'teaching as science' and its implication in class criticism. Yeolin Education Study, 20(2), 305-325.

Leithwood, K., Steinback, R., \& Ryan, S. (1997). Leadership and team learning in secondary schools. School Leadership and Management, 17(3), 303-326. https:// doi.org/10.1080/13632439769863

Levine, T.H., \& Marcus, A.S. (2010). How the structure and focus of teachers' collaborative activities facilitate and constrain teacher learning. Teaching and Teacher Education, 26(3), 389-398.

Lieberman, A., \& Miller, L. (2011). Learning communities. Staff Development, 32(4), 16-20.

Lloyd-Zannini, L.P. (1998). A review of Elliot Eisner's Cognition and curriculum reconsidered. Gifted Child Quarterly, 42(1), 63-64.

Lortie, D.C. (2002). Schoolteacher: A sociological study. University of Chicago Press.

Lyons, W., Thompson, S., \& Timmons, V. (2016). We are inclusive. We are a team. Let's just do it: Commitment, collective efficacy, and agency in four inclusive schools. International Journal of Inclusive Education, 20(8), 889-907. https://doi.org/10.1080/13603116.2015.1122841

Maslin-Ostrowski, P., Drago-Severson, E., Ferguson, J., Marsick, V.J., \& Hallett, M. (2018). An innovative international community engagement approach: Story circles as catalysts for transformative learning. Journal of Transformative Education, 16(2), 130-150. https://doi. org/10.1177/1541344617707840

McRae, M.B., \& Short, E.L. (2010). Racial and cultural dynamics in group and organizational life: Crossing boundaries (pp. 79-92). Thousand Oaks, CA: Sage.

Mead, G.H., \& Morris, C.V. (1934). Mind, Self, and Society. The University of Chicago Press.

Mezirow, J. (2003). Transformative Learning as Discourse. Journal of Transformative Education, 1(1), 58-63. https://doi.org/10.1177/1541344603252172

Mitchell S.D. (1992). Artistic school management of Waldorf school.

Moolenaar, N.M. (2010). Ties with potential: Nature, antecedents, and consequences of social networks in school teams. PhD Thesis, University of Amsterdam

Neumerski, C.M. (2013). Rethinking instructional leadership, a review: What do we know about principal, teacher, and coach instructional leadership, and where should we go from here? Educational Administration Quarterly, 49(2), 310-347.

New York State Education Department (NYSED). (2019). Educator Diversity Report. Retrieved from http://www.nysed.gov/common/nysed/files/programs/educator-quality/educator-diversity-reportdecember-2019.pdf

Ohlsson, J. (2013). Team learning: Collective reflection processes in teacher teams. Journal of Workplace Learning, 25(5), 296-309.

Opengart, R. (2005). Emotional intelligence and emotion work: Examining constructs from an interdisciplinary framework. Human Resource Development Review, 4(1), 49-62.

Pieterse, N.A., van Knippenberg, D., \& van Ginkel, P.W. (2011). Diversity in goal orientation, team reflexivity, and team performance. Organizational Behavior and Human Decision Processes, $114,153-164$.

Runhaar, P., ten Brinke, D., Kuijpers, M., Wesselink, R., \& Mulder, M. (2014). Exploring the links between interdependence, team learning and a shared understanding among team members: The case of teachers facing an educational innovation. Human Resource Development International, 17(1), 67-87.

Schapiro, S.A., Wasserman, I.L., \& Gallegos, P.V. (2012). Group work and dialogue: Spaces and processes for transformative learning in relationships. In E.W. Taylor \& P. Cranton (Eds.), The handbook for transformative learning (pp. 355-372). Jossey Bass.

Sharon, D.K., \& Karen, S.L. (1997). Administrative support and teacher leadership in schools implementing reform. Educational Administration Quarterly, 33(3), 261-289. 
Sheard, M., \& Sharples, J. (2016). School leaders' engagement with the concept of evidence-based practices as a management tool for school improvement. Educational Management, Administration and Leadership, 44(4), 668-687. https://doi.org/10.1177/1741143215580138

Shippers, M.C., Edmondson, A.C., \& West, M.A. (2014). Failure team reflexivity as an antidote to team information-processing. Small Group Research, 45(6) 731-769.

Spillane, J.P., \& Healey, K. (2010). Conceptualizing school leadership and management from a distributed perspective: An exploration of some study operations and measures. Elementary School Journal, 111(2), 253-281.

Troen, V., \& Boles, K. (2012). The power of teacher teams. Corwin Press.

Tyler, J.A., \& Swartz, A.L. (2012). Storytelling and transformative learning. In E.W. Taylor \& P. Cranton (Eds.), The handbook of transformative learning: Theory, research, and practice (pp. 455-470). John Wiley and Sons.

van Knippenberg, D., \& Mell, N.J. (2016). Past, present, and potential future of team diversity research: From compositional diversity to emergent diversity. Organizational Behavior and Human Decision Processes, 136, 135-145.

Vangrieken, K., Dochy, F., \& Raes, E. (2016). Team learning in teacher teams: Team entitativity as a bridge between teams-in-theory and teams-in-practice. European Journal of Psychology of Education, 31(3), 275-298. https://doi.org/10.1007/s10212-015-0279-0

Vangrieken, K., Dochy, F., Raes, E., \& Kyndt, E. (2015). Teacher collaboration: A systematic review. Educational Research Review, 15, 17-40.

Voogt, J., Westbroek, H., Handelzalts, A., Walraven, A., McKenney, S., Pieters, J., \& De Vries, B. (2011). Teacher learning in collaborative curriculum design. Teaching and Teacher Education, 27(8), 1235-1244. https://doi.org/10.1016/j.tate.2011.07.003

Wanda, E., Lyons, E.W., Thompson, S.A., \& Timmons, V. (2016) 'We are inclusive. We are a team. Let's just do it': Commitment, collective efficacy, and agency in four inclusive schools. International Journal of Inclusive Education, 20(8), 889-907.

Watkins, K.E., \& Marsick, V.J. (2010). Group and organizational learning. In A. Rose, C. Kasworm, \& J. Ross-Gordon (Eds.), Handbook of Adult and Continuing Education (pp. 59-68). Thousand Oaks, CA: Sage Publications.

Weiss, C.H., Cambone, J., \& Wyeth, A. (1992). Trouble in paradise: Teacher conflicts in shared decision making. Educational Administration Quarterly, 28(3), 350-367. https://doi.org/10.1177/0013161X92028003007

Wells, L. (1995). The group as a whole: A systematic socioanalytic perspective on interpersonal and group relations. In J. Gillette \& M. McCollom (Eds.), Groups in context: A new perspective on group dynamics. University Press of America.

West, L., Fleming, T., \& Finnegan, F. (2013). Connecting Bourdieu, Winnicott, and Honneth: Understanding the experiences of non-traditional learners through an interdisciplinary lens. Studies in the Education of Adults, 45(2), 119-134.

Widmann, A., \& Mulder, H.R. (2018). Team learning behaviours and innovative work behaviour in work teams. European Journal of Innovation Management, 21(3), 501-520.

Wijnia, L., Kunst, E., Van Woerkom, M., \& Poell, R. (2016). Team learning and its association with the implementation of competence-based education. Teaching and Teacher Education, 56, 115-126. http://dx.doi.org/10.1016/j.tate.2016.02.006

Yorks, L., \& Kasl, E. (2002). Toward a theory and practice for whole-person learning: Reconceptualizing experience and the role of affect. Adult Education Quarterly, 52(3), 176-192. https://doi.org/10.1177/07417136020523002

Youn, C., \& Park, S. (2012). Theoretical development of cultural historical activity theory. Journal of Lifelong Education, 18(3), 113-139.

Zimmerman, D.P., Roussin, J., \& Garmston, R.J. (2019). Transforming teamwork: Cultivating collaborative cultures. Corwin Press. 